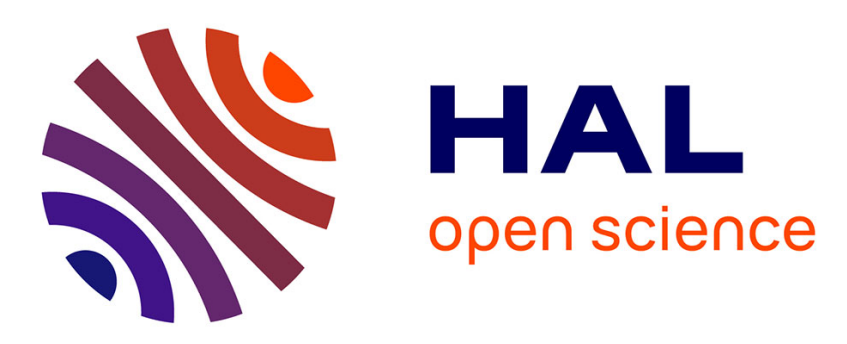

\title{
Mechanical and Microstructural Studies of (111) Au/Ni Multilayers
}

S. Labat, O. Thomas, P. Gergaud, A. Charaï, Claude Alfonso, L. Barrallier, B. Gilles, A. Marty

\section{> To cite this version:}

S. Labat, O. Thomas, P. Gergaud, A. Charaï, Claude Alfonso, et al.. Mechanical and Microstructural Studies of (111) Au/Ni Multilayers. Journal de Physique IV Proceedings, 1996, 06 (C7), pp.C7-135C7-142. 10.1051/jp4:1996715 . jpa-00254503

\section{HAL Id: jpa-00254503 https://hal.science/jpa-00254503}

Submitted on 1 Jan 1996

HAL is a multi-disciplinary open access archive for the deposit and dissemination of scientific research documents, whether they are published or not. The documents may come from teaching and research institutions in France or abroad, or from public or private research centers.
L'archive ouverte pluridisciplinaire HAL, est destinée au dépôt et à la diffusion de documents scientifiques de niveau recherche, publiés ou non, émanant des établissements d'enseignement et de recherche français ou étrangers, des laboratoires publics ou privés. 


\title{
Mechanical and Microstructural Studies of (111) Au/Ni Multilayers
}

\author{
S. Labat, O. Thomas, P. Gergaud, A. Charai*, C. Alfonso*, L. Barrallier**, B. Gilles*** and \\ A. Marty*** \\ MATOP, URA 1530 du CNRS, Faculté de Saint Jérôme, 13397 Marseille cedex 20, France \\ * EDIFIS, URA 443 du CNRS, Faculté de Saint Jérôme, 13397 Marseille cedex 20, France \\ ** MécaSurf, CER ENSAM, 13617 Aix-en-Provence cedex 1, France \\ *** CEA/DRFMC/SP2M, Centre d'Etudes Nucléaires, 38054 Grenoble cedex 9, France
}

\begin{abstract}
Résumé : Des multicouches Au/Ni ont été élaborées par EJM (Epitaxie par Jet Moléculaire) sur une couche tampon de cuivre lui même déposé sur silicium (001). Les contraintes internes de ces multicouches ont été déterminées par diffraction des rayons $\mathrm{x}$ ainsi que par réflectométrie laser. Elles montrent un état de cohérence entre les couches. D'autre part les mesures par rayons $\mathrm{X}$ montrent une forte dilatation de la maille du nickel. Ceci peut être interprete comme un effet de mélange or/nickel.
\end{abstract}

\section{INTRODUCTION}

The knowledge of the microstructure and strain in metallic multilayers is of great interest to explain their specific properties (magnetic, mechanical...). Most of the studies have been performed on samples prepared by sputtering. The present paper is devoted to MBE Au/Ni multilayers. Their structure and state of strain were investigated by $x$-ray diffraction.

\section{EXPERIMENTAL}

\subsection{Growth}

$\mathrm{Au}-\mathrm{Ni}$ multilayers were grown by Molecular Beam Epitaxy (M.B.E.) on a Cu buffer $(500 \AA$ thick) deposited on (100) Si, $100 \mu \mathrm{m}$ thick. Prior to the multilayer deposition the Cu buffer was in-siat annealed at $150^{\circ} \mathrm{C}$ to get a smoother surface. To induce a strong $\langle 111\rangle$ axis texture for the multilayer, the first deposited layer was $\mathrm{Au}$. Six different samples have been grown with the same thickness ratio between $\mathrm{Au}$ and $\mathrm{Ni}$ (1:1). All the multilayers are $1200 \AA$ thick except the $39 \AA$ period one which is $850 \AA$ thick. From the superlattice lines spacings it is possible to extract the superperiod with an accuracy less than one angstrom. Superperiods have been determined for the 6 samples : $9,19,27,35,39$ and $52 \AA$.

\subsection{Laser scanning}

The residual stresses of the multilayered film acts on the substrate and bends it. The measurement of the sample curvature yields the biaxial stress of the film [1]. For this measurement the scanning laser method described by Flinn and Gardner [2] was used. For our samples which are $2 \mathrm{~cm}$ long this device provides an accuracy better than $1 \%$ on the radius of curvature for uniform spherical curvatures of 70 meters and allows radii up to $7 \mathrm{kms}$ to be measured. The Stoney formula, taking into account the initial curvature, was used to deduced the average film stress. The difference of curvature only represent the action of the residual stresses of the film on the substrate. 


\subsection{X-ray diffraction}

The technique for lattice parameters determination which is more convenient is X-ray diffraction. The interatomic spacing $d_{h k l}$ is taken as a strain gauge and Bragg's law provides a direct relationship between the strain $\varepsilon$ and the diffraction angle $\theta$ of the film:

$$
\varepsilon=-\cot \theta_{0} \cdot\left(\theta-\theta_{0}\right)
$$

This equation shows that the measurement of the deformation is made by the measurement of the shift $\Delta \theta=\theta-\theta_{0}$ of the layer's Bragg angle where $\theta_{0}$ and $\theta$ are respectively the diffraction angle before and after deformation. Therefore, the strain can not be determined if the angle $\theta_{0}$ is not known. This angle depends on the crystallographic structure of the analysed material and on the cell parameters. These parameters depend themselves on the chemical composition and of the density of point defects of the material. As internal strains induce also a variation of the interatomic spacing, and thus of the diffraction angle, the main problem consists in separating the contribution of the lattice parameter and that of the internal strains.

The classical method for stress and strain determination using X-ray diffraction is the wellknown $\sin ^{2} \psi$ method. It is based on the research of the interatomic spacing of one hkl family in different $(\phi, \psi)$ directions.

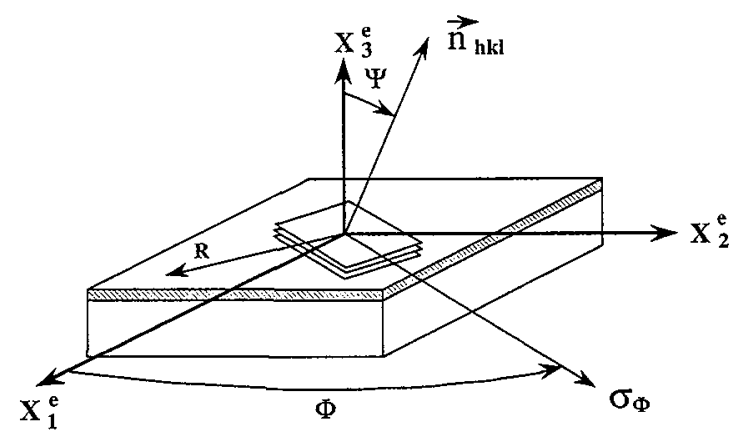

Figure 1 : Definition of the measurement direction as a function of $\phi$ and $\psi$.

In a randomly oriented polycrystalline material, one can find a diffracted signal in any $(\phi, \psi)$ direction and the relation between the measured deformation and $\sin ^{2} \psi$ is linear or elliptic. From this plot, the stress can be easily deduced. It is no more the case for a textured material. On one hand, the $\sin ^{2} \psi$ law is no more linear because the elastic constants will vary from one direction to an other, and on the other hand, if the texture is very strong the peak intensity can be too weak to be measured in any $(\phi, \psi)$ direction. In this case, one can use the crystallite group method [3], and in particular, if the texture is so strong that one can define one or several separate crystallographic orientations, the crystallite group method can be reduced to a single crystal stress analysis. This method is described elsewhere [4,5]. To summarize it, the stress determination is based on the measurements of different hkl planes belonging to the same crystallographic orientation. From at least six independant measurements, the metric tensor of the deformed state can be calculated. Knowing the undeformed metric tensor (the metric tensor before or without stress), the elastic strain tensor can be deduced and then using 
the Hooke's law all the stress tensor components. For a high enough accuracy, a minimum of fifteen peaks must be obtained. Thus, it is a quite long method. Furthermore, in the case of a cubic crystal the undeformed metric tensor is decribed only by the lattice parameter $a_{0}$. So using the hypothesis $\sigma_{33}=0$ (no stress applied in the direction of the normal to the surface), the unstressed lattice parameter of the material can be calculated without ambiguity.

For few cases, the analysis can be strongly simplified. When the normal of the film is parallel to specific crystallographic directions like the [111] of the cubic crystal, the mathematical analysis can be easily rewritten. The strain and stress are then related by the following relations :

- The general Hooke's law is: $\varepsilon_{\mathrm{ij}}=\mathrm{S}_{\mathrm{ijkl}} * \sigma_{\mathrm{kl}}$ where $\mathrm{S}_{\mathrm{ijkl}}$ is the elastic constants tensor of the crystal. Using the Voigt notation, this equation can also be written as : $\varepsilon_{\mathrm{i}}=S_{\mathrm{ij}} * \sigma_{\mathrm{j}}$ where $\varepsilon_{\mathrm{i}}=\varepsilon_{\mathrm{ij}}$ when $\mathrm{i}=\mathrm{j}, \varepsilon_{9-(\mathrm{i}+\mathrm{j})}=\varepsilon_{\mathrm{ij}}$ when $\mathrm{i} \neq \mathrm{j}$. For a cubic crystal, the elastic constants tensor can be described by only three terms : $S_{11}, S_{12}$ and $S_{44}$.

- For a crystal oriented (111)[1 $\overline{1} 0]$ in the sample basis, the relation between $\varepsilon^{\mathrm{s}} \mathrm{i}$ and

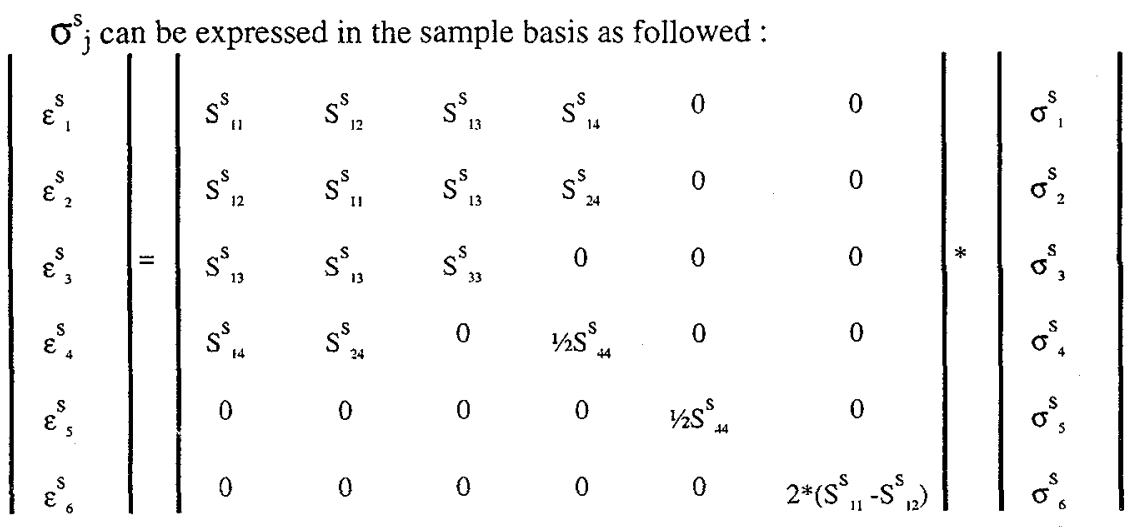

In an orthonormal coordinate system $(\mathbf{i}, \mathbf{j}, \mathbf{k})$, the strain $\varepsilon_{\phi \psi}$ in a $(\phi, \psi)$ direction can be defined by:

$$
\varepsilon_{\phi \psi}=n_{\mathrm{i}} \varepsilon_{\mathrm{ij}}^{\mathrm{s}} \mathrm{n}_{\mathrm{j}}
$$

where $\mathrm{n}$ is a vector depending on the angles $\phi$ and $\psi$.

$\mathrm{n}_{1}=\cos \phi \sin \psi$

$\mathrm{n}_{2}=\sin \phi \sin \psi$

$\mathrm{n}_{3}=\cos \psi$

As $\mathrm{X}$-ray diffraction only concerns a very thin layer of matter near the surface, it is reasonable to assume that no stress are applied on the free surface of the sample, i. e : $\sigma_{3}^{\mathrm{s}}=0$. Moreover, in most cases the symmetry of the substrate and of the deposition process leads to an isotropic biaxial state of stress in the plane of the thin film $\sigma_{1}^{\mathrm{s}}=\sigma_{2}^{\mathrm{s}}=\sigma$. This implies that the stress components $\sigma_{6}^{\mathrm{s}}, \sigma_{4}^{\mathrm{s}}$ and $\sigma_{5}^{\mathrm{s}}$ are also null (no compensation of the shear stresses between crystallites or between phases). Developping the relation (2) with (3), we obtain the following relations :

$$
\varepsilon_{\phi \psi}=\left(\left(S_{11}^{s}+S_{12}^{s}-2 . S_{13}^{s}\right) \sin ^{2} \psi+2 . S_{13}^{s}\right) \sigma
$$


This relation can be rewritten using the elastic constants expressed in the crystallographic basis :

$$
\varepsilon_{\phi \psi}=\left(1 / 2 S_{44} \sin ^{2} \psi+2 . S_{12}+{ }^{2} / 3\left(S_{11}-S_{12}-1 / 2 S_{44}\right)\right) \sigma
$$

One can thus observe that the strain versus $\sin ^{2} \psi$ plot is linear, and that the slope of the straitgh line is proportionnal to the stress multiplied by elastic constants. Moreover, assuming the upper hypothesis on the stress components and rewriting the equation (5), we can define a value of $\sin ^{2} \psi$ where the strain $\varepsilon_{\phi \psi}$ is null.

$$
\sin ^{2} \psi_{0}=-\left(2 S_{12}+{ }^{2} / 3\left(S_{11}-S_{12}-1 / 2 S_{44}\right)\right) /\left(1 / 2 S_{44}\right)
$$

For this particular angle $\psi_{0}$, the interatomic spacing $d_{\psi}$ is thus equal to the unstressed interatomic spacing $\mathrm{d}_{0}$, giving us, for a cubic crystal, the unstressed lattice parameter of the crystal $\mathrm{a}_{0}$.

So by plotting the strain $\varepsilon_{\phi \psi}$ versus $\sin ^{2} \psi$, the linearity of the curve implies or verifies the hypothesis of isotropic stress on the surface of the specimen. The slope of the straight line gives the stress, and from the strain at $\psi_{0}$, the unstressed lattice parameter of the cubic crystal can be deduced.

\section{Experimental conditions :}

The measurements have been performed using the two methods. As a first approach, we used on one sample the method based on the metric tensor determination in order to verify the isotropic biaxial state of stress. At least $12 \mathrm{~d}$-spacings have been measured belonging to the following hkl families : (311), (222), (220) and (200). Then, we used the relation (5) with only four or five planes.

These measurements have been obtained on different four circles diffractometers, with different wavelengths $(\mathrm{Cu}, \mathrm{Co}, \mathrm{Fe})$, and with a position sensitive detector or a point detector. In some cases, the separation of superimposed peaks from nickel and from gold was achieved using a profile fitting procedure with a pseudo-voigt function.

\section{RESULTS}

\subsection{Microstructure}

A symmetrical $\theta / 2 \theta$ scan explores only a small part of the reciprocal space, it probes only lattice planes parallel to the surface of the sample. It is not sufficient to determine the crystallites orientations present in the film. Firstly the symmetrical scan allows only the determination of the axis texture and doesn't give any information on the crystallographic distribution around this axis.

On copper the 220 pole figure (fig2a) shows a unique (100) [001] orientation of the layer // to X2 axis, and on gold the 111 pole figure (fig2b) shows 4 different orientations around the $\left\langle 111>\right.$ axis. Their in-plane $\left[1 \overrightarrow{1} 0\right.$ ] directions are rotated by $15^{\circ}, 45^{\circ}, 75^{\circ}$ and $105^{\circ}$ from the X2 axis of the poles figure. The same texture has been found for nickel layers. Thus the following epitaxial relationship are deduced: $(100) \mathrm{Cu}<011>\mathrm{Cu} / /(100) \mathrm{Si}<010>\mathrm{Si}$, and four differents variants for $\mathrm{Au}$ and $\mathrm{Ni}$ : (111) $\mathrm{Au}, \mathrm{Ni}<110>\mathrm{Au}, \mathrm{Ni} / /(100) \mathrm{Cu}<01 \mathrm{l}>\mathrm{Cu}$ are explained by the four directions $<011>$ of the $(100) \mathrm{Cu}$ plane. The 6 samples have the same texture. 


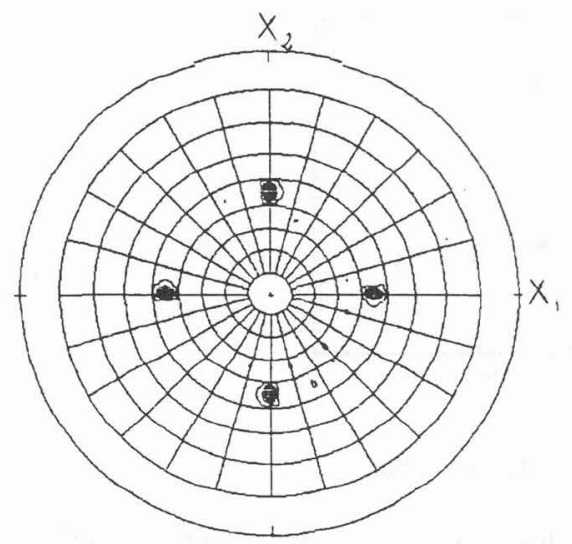

Figure 2a : Copper 220 pole figure $\psi\left\{0 . .80^{\circ}\right\}$

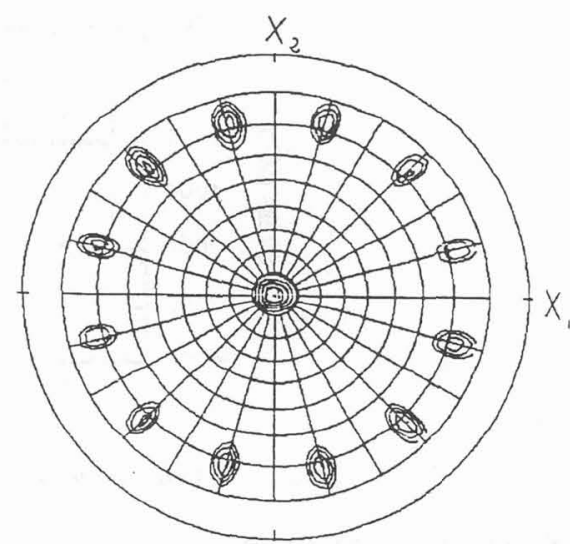

Figure 2b : Gold 111 pole figure $\psi\left\{0 . .80^{\circ}\right\}$

\subsection{Stress}

Figure 3 shows the stress measurement by laser scanning i.e. the substrate interaction stress. This average stress is tensile unlike the compressive stress found in sputtered $\mathrm{Au} / \mathrm{Ni}$ multilayers [6]. The large error bars on the value of stress for multilayers with a $39 \AA$ superperiod is due to an initial curvature sligthly stronger than for the other substrate.

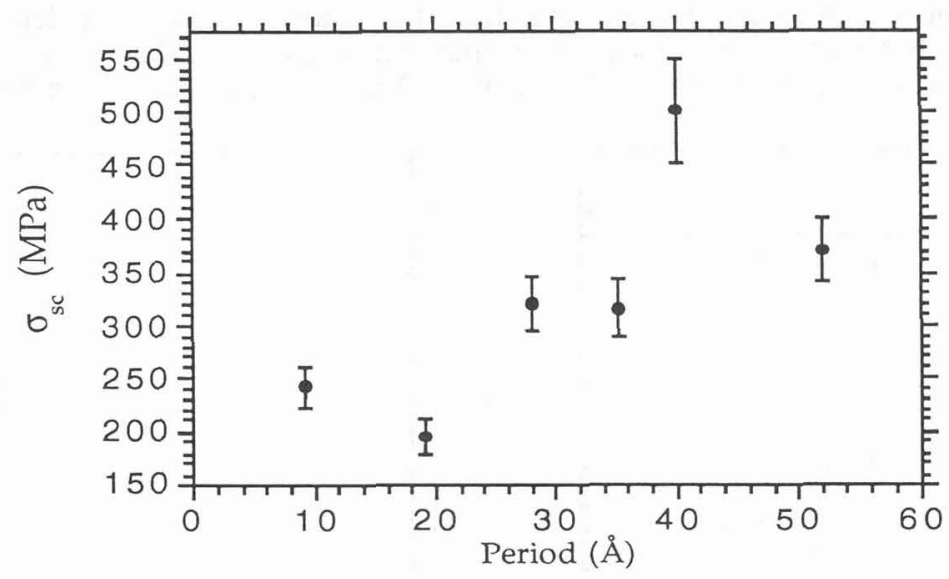

Figure 3: Average stress in multilayers film measured via the substrate curvature.

The resulting curvature variation is thus smaller, giving rise to a decreased accuracy in the measurement. Nevertheless a variation of the stress in the film with the period is evidenced. The stress decreases when the superperiod decreases. 


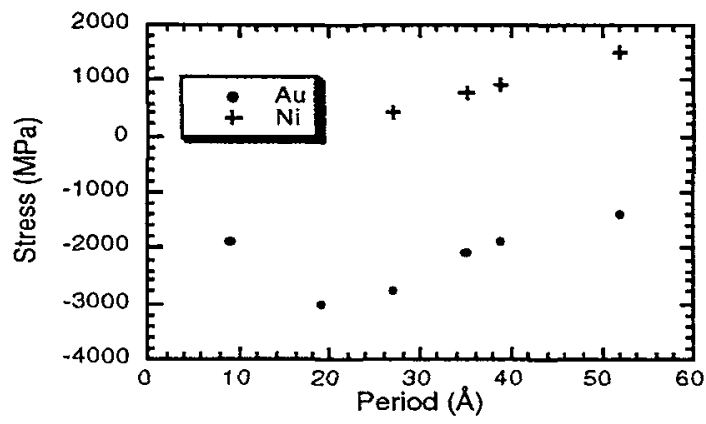

Figure 4: Stresses measured by X-Ray diffraction.

X-ray diffraction allows one to separate the contribution from each constituent of the film. Copper is always under tensile stress of about $200 \mathrm{MPa}$ for each sample. The variations of the stress for gold and for nickel are reported in figure 4. Nickel is found under tension while gold is under compression. For a superperiod lower than $27 \AA$, the stresses in nickel can not be determined due to the weak intensity of the diffraction peaks. The sign of these residual stresses is in agreeement with an in-plane lattice coherency effect. But the stress is relaxed because if coherency was present between the two layers, the forces equilibrium applied at the interfaces would imply a $17800 \mathrm{MPa}$ compressive stress in gold and an identical tensile stress in nickel.

\subsection{Strain}

The unstressed parameters (figure 5a) have been deduced from the straight line $\sin ^{2} \psi$ vs $\varepsilon$ at the particular angle $\psi_{0}$. This angle calculated from the elastic constants [7] is equal to $36.7^{\circ}$ for pure nickel and $48.1^{\circ}$ for pure gold. In the case of mixing the elastic constants are calculated as a concentration weighted average and the stress free lattice parameter is determined self consistently. For gold the unstressed lattice parameter remains near the bulk value $4.0786 \AA$, while the nickel one is rather far from its bulk value $3.5238 \AA$ and reaches a maximum of $3.65 \AA$ for $\Lambda=19 \AA$.

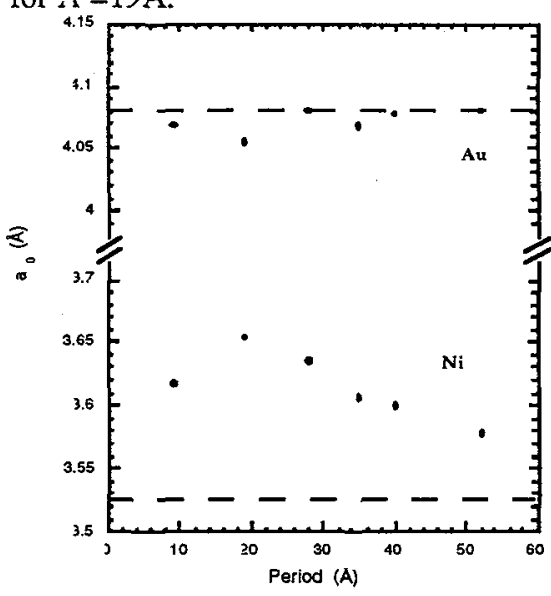

Figure 5a : Unstressed lattice parameters for gold and nickel.

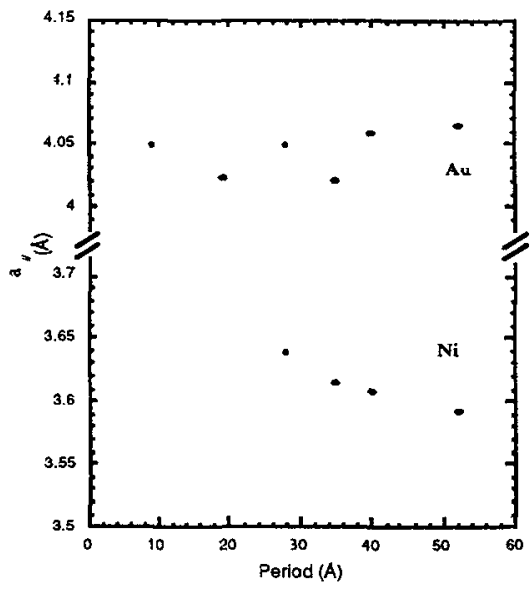

Figure $\mathbf{5 b}:$ in-plane extrapolated lattice parameters. 
From the extrapolation of the $\operatorname{Sin}^{2} \psi$ straight line to $\psi=90^{\circ}$ the in-plane parameter can be deduced. This value was not determined for nickel for a superperiod lower than $27 \AA$ for the same reason stated above. Figure $5 \mathrm{~b}$ evidences the incoherency between gold and nickel inplane lattice parameter (parameters averaged over the thickness of the layers). The variation of the in-plane lattice parameters for nickel is essentially due to the increase of the unstressed parameter, it is not coming from an elastic strain effect because the stress in $\mathrm{Ni}$ would be increasing too, that is not the case.

\section{DISCUSSION}

In the preceding paragraph, the expansion of the Ni unit cell has been attributed to the existence of a Au-Ni solid solution. According to Vegard law this would correspond to Au concentrations in $\mathrm{Ni}$ between 9 and $20 \%$. The solubility of $\mathrm{Au}$ in $\mathrm{Ni}$ is, however, $1 \%$ at room temperature (the deposition temperature). This implies that we would be dealing with out-of-equilibrium solutions. In the used deposition technique (MBE), the kinetic energy of the deposited atoms is too low to allow mixing via knock-in effects. Moreover our results would indicate that $\mathrm{Ni}$ is not incorporated in $\mathrm{Au}$ layers although $\mathrm{Ni}$ is more soluble in $\mathrm{Au}$ than $\mathrm{Au}$ is in $\mathrm{Ni}$. One possible interpretation for these results could be that $\mathrm{Au}$ segregates during growth on top of the deposited Ni. Indeed, Au surface energy is smaller than the Ni one.

Figure 6 reports on the variation of the tensile stress in nickel versus the gold concentration in the nickel layers. The gold concentration is extracted from the Ni unstressed parameter and the application of Vegard's law. The incorporation of gold atoms in the nickel layers leads to the relaxation of the tensile stress and thus of the elastic energy. This minimization of the elastic energy could be one of the driving force for intermixing.

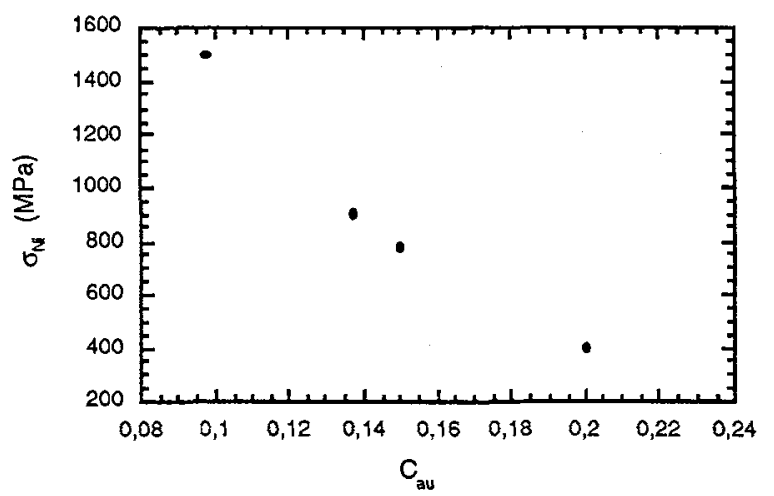

Figure 6: Stresses in nickel layer versus the gold concentration in nickel.

The role of the interfacial stress may be evidenced by comparing the substrate interaction stress with the stress determined by $x$ ray diffraction in nickel, gold and copper layers. Using the expression introduced by Ruud [8] establishing a force equilibrium :

$$
\sigma_{S C} t_{f}=\sigma_{C u} t_{C u}+\sigma_{A u} t_{A u}+\sigma_{N i} t_{N i}+2 f t_{f} / \Lambda
$$

where $\sigma_{\mathrm{Cu}}, \sigma_{\mathrm{Au}}, \sigma_{\mathrm{Ni}}$, are respectively the stress in copper, gold and nickel, $\sigma_{\mathrm{SC}}$ the substrate interaction stress ; $t_{\mathrm{f}}, \mathrm{t}_{\mathrm{Cu}}, \mathrm{t}_{\mathrm{Au}}, \mathrm{t}_{\mathrm{Ni}}$ are respectively the total thickness of the film , copper, gold and nickel ; $f$ the interfacial stress ; $\Lambda$ the superperiod. 


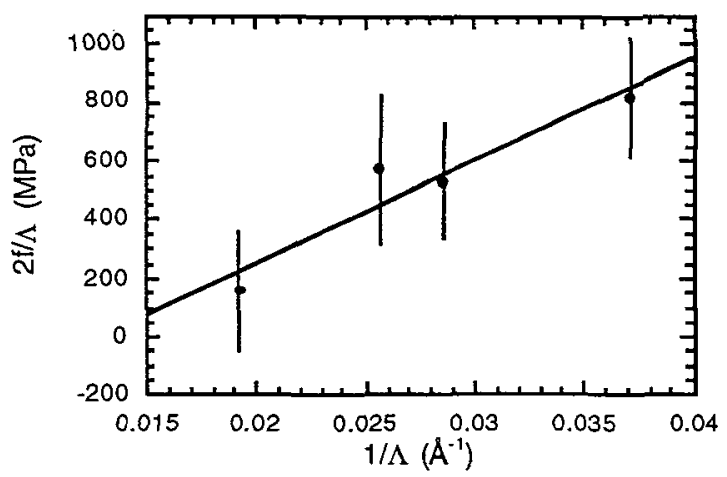

Figure 7: Interfacial Stress

The values of $2 \mathrm{f} / \Lambda$ are reported versus $1 / \Lambda$ in figure 7 . The thickness of gold and nickel layers are recalculated from the original ratio and taking into account the decrease of the gold layer thickness due to gold incorporation in nickel layers. We find $\mathrm{f}=1.7 \mathrm{~J} / \mathrm{m} 2$ that it is three times more than the value calculated by Streitz \& al [9] for non coherent interfaces: $0.58 \mathrm{~J} / \mathrm{m} 2$. A similar discrepancy with calculation was reported by [8].

\section{CONCLUSION}

We evidence a systematic increase of the lattice parameter of nickel in MBE deposited $\mathrm{Au} / \mathrm{Ni}$ multilayers. Gold is always under compressive stress while nickel is under tensile stress. The relaxation of stress in nickel follows the increase of gold concentration in nickel.

\section{REFERENCES}

[1] O. Thomas, P. Gergaud, S. Labat, L. Barrallier, A. Charaï, C. Alfonso, B. Gilles, A. Marty, 39ème Colloque de métallurgie de l'INSTN, in this proceeding

[2] P. Flinn, D. Gardner, W. Nix, IEEE Trans. Elec. Devices ED-34 (1987) 689.

[3] V. Hauk, W. K. Krug, R. W.M. Oudelhoven, L. Pintschovius, Metallkunde, 79 (1988) 159-163.

[4] L. Brillouin, 'Les tenseurs en mécanique et en élasticité', Masson and Cie Editors (1960).

[5] M. Barral, J. M. Sprauel, 'Residual stresses in science and technology', Macherauh and Hauk (1987) 265-273.

[6] S. Baker, W. Nix, J. Mater. Res., 9 (1994) 3145

[7] J. P. Hirth and J. Lothe, Theory of dislocations, McGraw-Hill (1968).

[8] J.A. Ruud, A. Witrouw, F. Spaepen, J. Appl. Phys. 74 (1993) 2517.

[9] F. H. Streitz, R.C. Cammarata, K. Sieradzki, Phys. Rev. B 49 (1994) 10707 